\title{
The effects of daylight saving time on vehicle crashes in Minnesota
}

\author{
Arthur Huang ${ }^{a, *}$, David Levinson ${ }^{b}$ \\ a University of Minnesota, Department of Civil Engineering, 500 Pillsbury Drive SE, Minneapolis, MN 55455 USA \\ ${ }^{\mathrm{b}} \mathrm{RP}$ Braun-CTS Chair of Transportation Engineering, University of Minnesota, Department of Civil Engineering, USA
}

\section{A R T I C L E I N F O}

Available online 25 November 2010

\section{Keywords:}

Daylight saving time

Vehicle crashes

Exposure

Traffic volume

\begin{abstract}
A B S T R A C T
Introduction: Daylight saving time (DST), implemented as an energy saving policy, impacts many other aspects of life; one is road safety. Based on vehicle crash data in Minnesota from 2001 to 2007, this paper evaluates long- and short-term effects of DST on daily vehicle crashes. Method: To provide evidence to explain the causes of more/fewer crashes in DST, we examine the impact of DST on crashes in four periods of a day: 3 a.m.-9 a.m., 9 a.m.-3 p.m., 3 p.m.-9 p.m., 9 p.m.-midnight. The effects of risk and exposure to traffic are also separated. Our statistical models not only include weather conditions and dummy variables for days in DST as independent variables, but also consider traffic volumes on major roads in different periods of a day. Our major finding is that the short-term effect of DST on crashes on the morning of the first DST is not statistically significant. Moreover, it is interesting to notice that while DST per se is associated with fewer crashes during dusk, this is in part offset because it is also associated with more traffic on roads (and hence more crashes). Our path analysis shows that overall DST reduces crashes. Impact on industry: Daylight saving time can lead to fewer crashes on roads by providing better visibility for drivers.
\end{abstract}

(c) 2010 National Safety Council and Elsevier Ltd. All rights reserved.

\section{Introduction}

Daylight saving time (DST) in the United States dates to World War I as an energy saving measure, and in its current incarnation was officially enacted by Congress in 1974. DST aims to match activities with hours of daylight by adjusting the standard time (ST) forward or backward one hour at different times of year. This keeps sunset and sunrise one hour later in spring, summer, and early fall, so that people have one more evening hour of daylight (and therefore one less morning hour of daylight) in DST (Coate \& Markowitz, 2003). In addition to its claimed feature of energy conservation, DST may impact many other aspects of daily life, one of which is road safety. Therefore, quantitatively examining the effects of DST on road safety is of interest.

The relationship between DST and road injuries or fatalities has been a topic of extensive research. Sood and Ghosh (2007) indicated that there were generally two schools in studying the effects of DST on road safety, which respectively concentrated on long-term effects and shortterm effects. Here short-term effects indicate the impact of DST on vehicle crashes in a few days after time changes, while long-term effects refer to its impact of a longer time period, say, a few months or year round.

\footnotetext{
* Corresponding author.

E-mail addresses: huang284@umn.edu (A. Huang), dlevinson@umn.edu (D. Levinson).

URL: http://nexus.umn.edu (D. Levinson).
}

To be specific, one of the schools claimed that DST in the long run decreases vehicle crashes due to better visibility in the evenings, reducing the likelihood of crashing in darkness. Table 1 summarizes previous research. These studies argued that if driving in darkness contributes to more traffic crashes, the delayed sunset time can lead to fewer crashes.

The other school contended that time change to DST resulted in more vehicle crashes in the short run. Some representative studies are reviewed in Table 2, where many research reported an increase of general/fatal crashes after time change in spring. The main hypothesis was that time change in spring deprived people of one-hour sleep, which, in the short run, could induce drivers' sleepiness or fatigue while driving. Some clinical research performed controlled experiments to examine the relationship between hours of sleep and drivers' response time and vigilance; their main conclusion was that one-hour less sleep can boost the rise of traffic crashes. In addition, some other studies found that time change to DST was associated with an increase of fatal vehicle crashes, and attributed it to possible drivers' alcohol-drinking or late-night driving behavior out of one extra hour during dusk.

In contrast, other research found that time change did not have a statistically significant impact on vehicle crashes. For example, Lambe and Cummings (2000), based on the Swedish vehicle crash data from 1984 to 1995 , concluded that the shifts to and from DST had no effect on vehicle crashes. Vincent (1998) also drew a similar conclusion using the crash data from Canada.

While different data may produce different results, the effects of DST do not seem to have been sufficiently investigated. First of all, 
Table 1

Selected previous studies supporting positive effects of daylight saving time on road safety.

\begin{tabular}{|c|c|c|c|}
\hline Study & Data set & Method & Results \\
\hline Meyerhoff (1978) & $\begin{array}{l}\text { US fatal vehicle crash } \\
\text { data }(1973-1974)\end{array}$ & Fourier analysis & $\begin{array}{l}\text { Several weeks after time change from ST to DST } \\
\text { witnessed a net reduction of about } 0.7 \% \text { in fatal } \\
\text { vehicle crashes; little effect of DST was found on } \\
\text { fatal crashes in the winter. }\end{array}$ \\
\hline Ferguson (1995) & $\begin{array}{l}\text { US fatal vehicle crash } \\
\text { data (1987-1991) }\end{array}$ & $\begin{array}{l}\text { Generalized linear models } \\
\text { (GLM) }\end{array}$ & $\begin{array}{l}\text { Year-round DST from } 1987 \text { to } 1991 \text { would have } \\
\text { helped reduce } 901 \text { fatal crashes ( } 727 \text { involving } \\
\text { pedestrians, } 174 \text { involving vehicle occupants). }\end{array}$ \\
\hline Broughton and Sedmand (1989) & UK accident data (1968-1971) & GLM & $\begin{array}{l}\text { Year-round DST in } 1987 \text { would have helped reduce } \\
159 \text { fatal crashes, } 654 \text { seriously injured crashes } \\
\text { and } 1247 \text { overall injured crashes. }\end{array}$ \\
\hline Hillman (1989) & Survey data in Britain & GLM & $\begin{array}{l}\text { Transferring one hour of daylight from the early } \\
\text { morning to daytime may save more lives on road, } \\
\text { especially for rural areas. }\end{array}$ \\
\hline Ward et al. (1994) & Survey data in Northampton, England & GLM & $\begin{array}{l}237 \text { pedestrians were injured per } 100 \text { million road } \\
\text { in darkness, compared with } 52 \text { pedestrians in daylight. } \\
\text { This implied that better light condition at night could } \\
\text { lead to fewer crashes. }\end{array}$ \\
\hline Adams (2005) & UK crash data (1968-1971) & GLM & $\begin{array}{l}\text { Year-round DST was associated with a } 6.9 \% \\
\text { decrease in serious or fatal road injuries of children. }\end{array}$ \\
\hline Coate and Markowitz (2003) & US fatal vehicle crash data (1998-1999) & GLM & $\begin{array}{l}\text { Year-round DST would reduce pedestrian fatalities in } \\
\text { morning peak hours and afternoon peak hours by } 13 \% \text {; } \\
\text { motor vehicle occupant fatalities would downsize by } 3 \% \text {. }\end{array}$ \\
\hline Broughton and Stone (1998) & UK vehicle crash data (1969 to 1994) & GLM & $\begin{array}{l}\text { Year-round DST would reduce } 104 \text { to } 138 \text { fatal crashes } \\
\text { per year. }\end{array}$ \\
\hline Broughton, Hazelton, and Stone (1999) & $\begin{array}{l}\text { UK vehicle crash data (1969-1973 } \\
\text { and 1985-1994), USA (19911995) }\end{array}$ & Statistical models & $\begin{array}{l}\text { Year-round DST from } 1987 \text { to } 1991 \text { would have helped } \\
\text { reduce } 833 \text { fatal crashes involving pedestrians, and } 140 \\
\text { fatal crashes involving vehicle occupants. }\end{array}$ \\
\hline Stevens and Lord (2006) & $\begin{array}{l}\text { Fatal and nonfatal jnjury } \\
\text { Crashes in Texas }\end{array}$ & GLM & $\begin{array}{l}\text { Time change to DST can improve traffic safety due to } \\
\text { better light condition. }\end{array}$ \\
\hline
\end{tabular}

most studies only looked at crashes for the whole day, which, while useful in comparing crashes in DST and ST on a daily basis, cannot provide insight about the effects of DST on different periods of a day. Therefore, to test the hypotheses about the reasons for more crashes (such as sleepiness or late-night driving) calls for studying crashes in different time periods of a day where the causes may exist. Second, previous research has not addressed the issue of exposure. In addition to a direct influence on crashes, DST may change traffic flow patterns near dawn and dusk, which can further impact crashes.

This paper, based on the crash data in Minnesota (MN) from 2001 to 2007, endeavors to fill this research niche by considering vehicles' exposure to traffic. The research question is whether the policy of DST can impact vehicle crashes in MN. Over the long-term, we hypothesize that the impact of DST on crashes includes two parts: exposure and risk of crashes. First, in terms of exposure, we hypothesize that DST may reduce traffic during dawn yet increase traffic during dusk. Second, DST may lower the risk of crashes during dusk due to one more hour of visibility for drivers. In the short term, DST, per se, may be associated with more crashes on morning of the first day of DST because of drivers' tiredness/sleepiness after losing one hour's sleep.
The rest of the paper is organized as follows. Section 2 describes the background of daylight saving time and the dates of time change in the United States. Section 3 shows the results of exploratory analysis on crashes. Section 4 introduces the data sets used in this research. In Section 5, statistical models are constructed to assess the effects of DST on crashes in MN; two-stage least squared models are built to look at the effects of DST on traffic as well as on crashes. The results and analysis are depicted in Section 6. Lastly, Section 7 concludes the paper.

\section{Background of daylight saving time}

The idea of daylight saving time is to transfer an hour of morning daylight to the evening. It is achieved by setting clocks ahead one hour in spring and turning the clocks back one hour in fall. To illustrate, Fig. 1 plots the times of sunrise and sunset (with DST adjustment as separate lines) in Minneapolis/St. Paul, MN, USA for 2007. Note that not all places in the United States observe daylight time; in particular, Hawaii and most of Arizona do not use it. In 2006 and earlier years, DST begins at 2 a.m. local time on the first Sunday in April, and ends at

Table 2

Selected previous studies supporting negative effects of daylight saving time on road safety.

\begin{tabular}{|c|c|c|c|}
\hline Study & Data set & Method & Results \\
\hline Ledger (1994) & US vehicle crashes 1998 & Human capital approach & $\begin{array}{l}\text { Sleepiness and sleep disorders are major } \\
\text { causes of traffic crashes. }\end{array}$ \\
\hline Coren (1996a) & US fatal crash data ( 3 years) & GLM & $\begin{array}{l}\text { Sleep loss in spring can increase the likelihood } \\
\text { of fatal crashes on road. }\end{array}$ \\
\hline Coren (1996b) & Canada traffic crash data (1991 to 1992) & GLM & $\begin{array}{l}\text { Deprivation of one-hour sleep can boost the risk } \\
\text { of traffic crashes. }\end{array}$ \\
\hline Hicks, Lindseth, and Hawkins (1983) & US fatal vehicle crashes & Qualitative analysis & $\begin{array}{l}\text { Crashes increased significantly in the first seven } \\
\text { days after the time change both in spring and in fall. }\end{array}$ \\
\hline Hicks, Davis, and Hicks (1998) & Fatal crashes in New Mexico (1989-1992) & GLM & $\begin{array}{l}\text { Percentage of alcohol-related fatal crashes increased } \\
\text { significantly in the first seven days after the time change. }\end{array}$ \\
\hline Varughese and Allen (2001) & US fatal vehicle crashes ( 21 years) & GLM & $\begin{array}{l}\text { Crashes on Sundays in fall rised significantly after shifting } \\
\text { from DST to ST, which may be highly associated with drivers' } \\
\text { alcohol consumption. }\end{array}$ \\
\hline
\end{tabular}




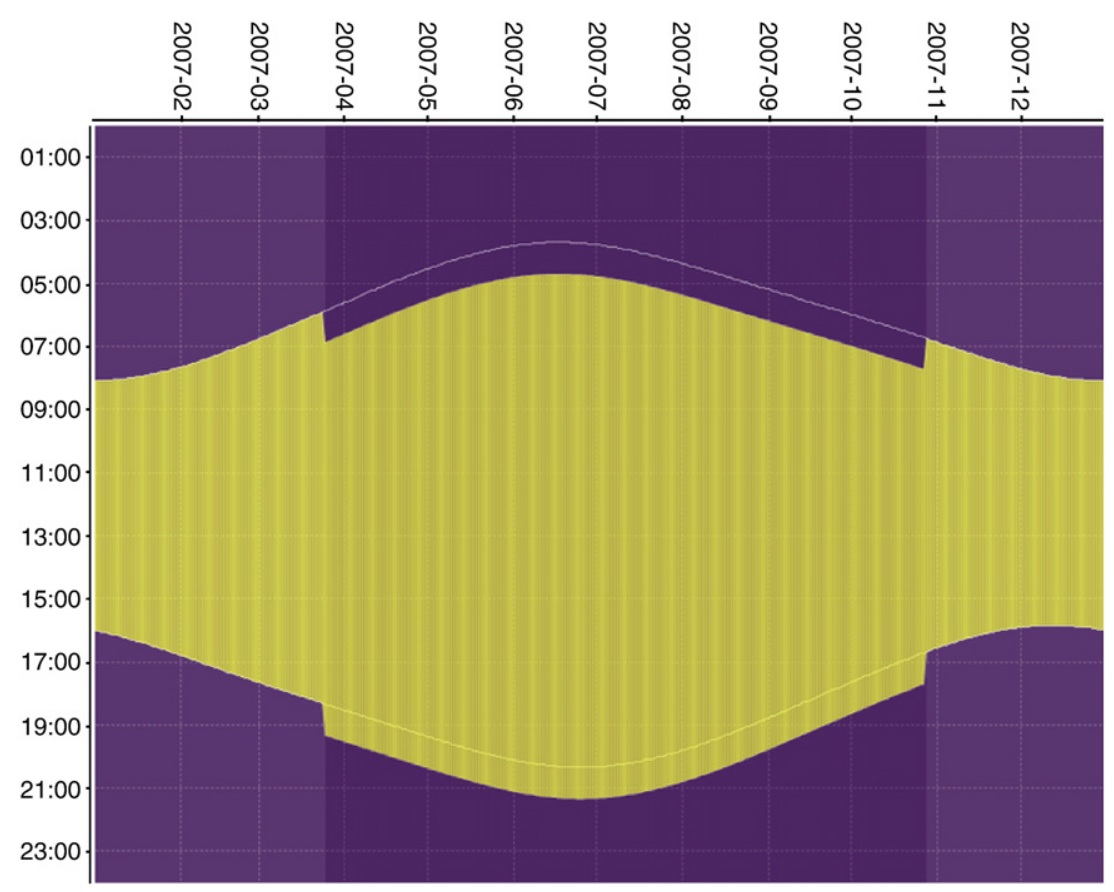

Fig. 1. Times of sunrise and sunset (with DST adjustment as separate lines) in Minneapolis/St. Paul, MN, USA for 2007 (plotted by Daylight Chart 3.0 (Fatehi, 2009 )).

Table 3

Beginning and ending dates of daylight saving time in the US (Hawaii and Arizona excluded).

\begin{tabular}{lll}
\hline Year & DST Begins & DST ends \\
\hline 2000 & $4 / 2$ & $10 / 29$ \\
2001 & $4 / 1$ & $10 / 28$ \\
2002 & $4 / 7$ & $10 / 27$ \\
2003 & $4 / 6$ & $10 / 26$ \\
2004 & $4 / 4$ & $10 / 31$ \\
2005 & $3 / 3$ & $10 / 30$ \\
2006 & $3 / 2$ & $10 / 29$ \\
2007 & $3 / 11$ & $11 / 4$ \\
2008 & $3 / 9$ & $11 / 2$ \\
2009 & $3 / 8$ & $11 / 1$ \\
\hline
\end{tabular}

2 a.m. local time on the last Sunday in October. Starting in 2007, DST begins on the second Sunday in March, and ends on the first Sunday in November. The dates of time change from 2000 to 2009 are shown in Table 3.

Before we perform statistical analysis, it may be important to first obtain an intuitive sense of the trend of crashes as time changes (from ST to DST or from DST to ST).

\section{Exploratory analysis}

The exploratory analysis involves two parts. First, based on historical crash data in Minnesota (2001-2007), this study plots weekly crashes during the 16 weeks crossing the time change in spring (from ST to DST) and in fall from (DST to ST), categorized by four parts of day (hereafter dayparts) (3 a.m.-9 a.m., 9 a.m.-3 p.m., 3 p.m.-9 p.m., 9 p.m.-midnight). ${ }^{1}$ Fig. 2 shows the crashes during the transition period in spring. The first week in DST in all four sections has fewer crashes than its previous week, although afterwards crashes rise again. However, the average weekly crashes in the first eight weeks in DST are lower than the last eight weeks in ST. Fig. 3 sketches weekly crashes

\footnotetext{
${ }^{1}$ While our major interests are in the dawn and dusk periods, we also would like to explore if there is any ripple effect for other dayparts.
}

during the transition period in fall. During 3 p.m. to 9 p.m., the first week in ST suffers from more crashes than the last week in DST, while the opposite holds for $3 \mathrm{a} . \mathrm{m}$. to $9 \mathrm{p}$.m. For other time periods, the difference is not easy to be discerned. It is interesting to notice that in the 5th week in ST (around the first week in November), there is a surge of crashes for most periods of a day. This is around the time when snow starts to fall in Minnesota, increasing the probability of crashes.

Second, to inspect the short-term effect of DST, we single out the first day (Sunday) of time change and compare it with other Sundays. Fig. 4 displays the crashes on Sundays during the transition period in spring. It can be found that crashes decline sharply in the 3rd week before DST, and level off afterwards. For 9 a.m.-3 p.m. the first week in DST has slightly fewer crashes than the last week in ST; yet during other periods more crashes happen in the first week of DST. Fig. 5 further shows the Sunday crashes during the transition period in fall. The first Sunday in ST seems to be afflicted with more crashes than its previous week in all four periods; the difference of crashes, nevertheless, are generally less than $5 \%$.

Overall, based on the above analysis, it is hard to pinpoint the effect of time change. For example, as shown in Figs. 2 and 4, the first day and first week of DST have fewer crashes than their previous ones, but a longer effect of time change cannot be clearly eyeballed. In addition, we have not yet controlled for other crash-related factors such as weather and season. Further statistical analysis is thus needed.

One frequently asked question is: how much more dangerous, if any, is travel in daylight saving time? This question includes two aspects. First, what natural conditions in DST, different from those in ST, lead to more crashes? Second, what changes in the amount of driving happen? The next two sections will introduce the variables and models used to answer this question.

\section{Data}

To answer the first aspect of the question, the data we use are the crash data of Minnesota, USA from year 2001 and 2007. The crash data set, complied by the Minnesota Office of Traffic Safety (OTS), documents all reported vehicle-related crash data for Minnesota. The complied crash data have one record for each crash and contain overall information about the crash, such as date and time, location, whether property besides vehicles was damaged, and type of roadway. 


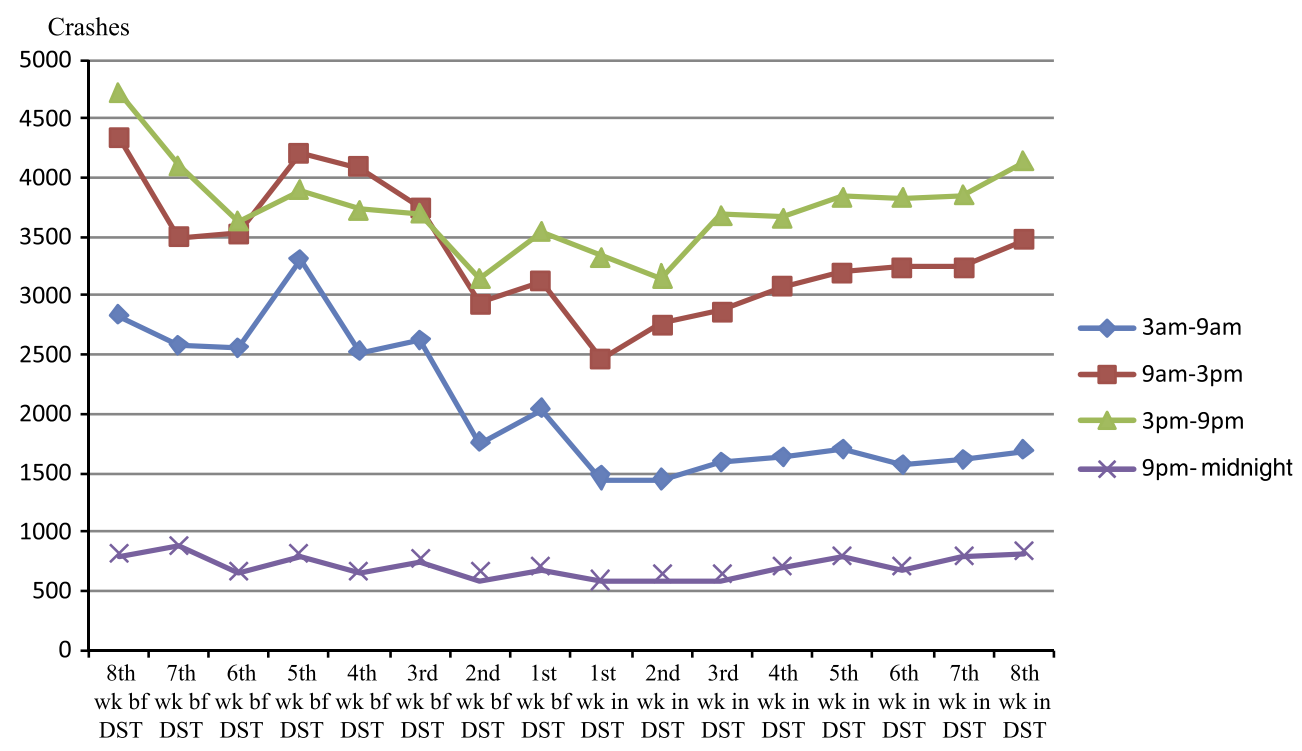

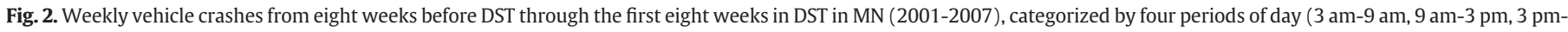
9 pm, 9 pm-midnight)

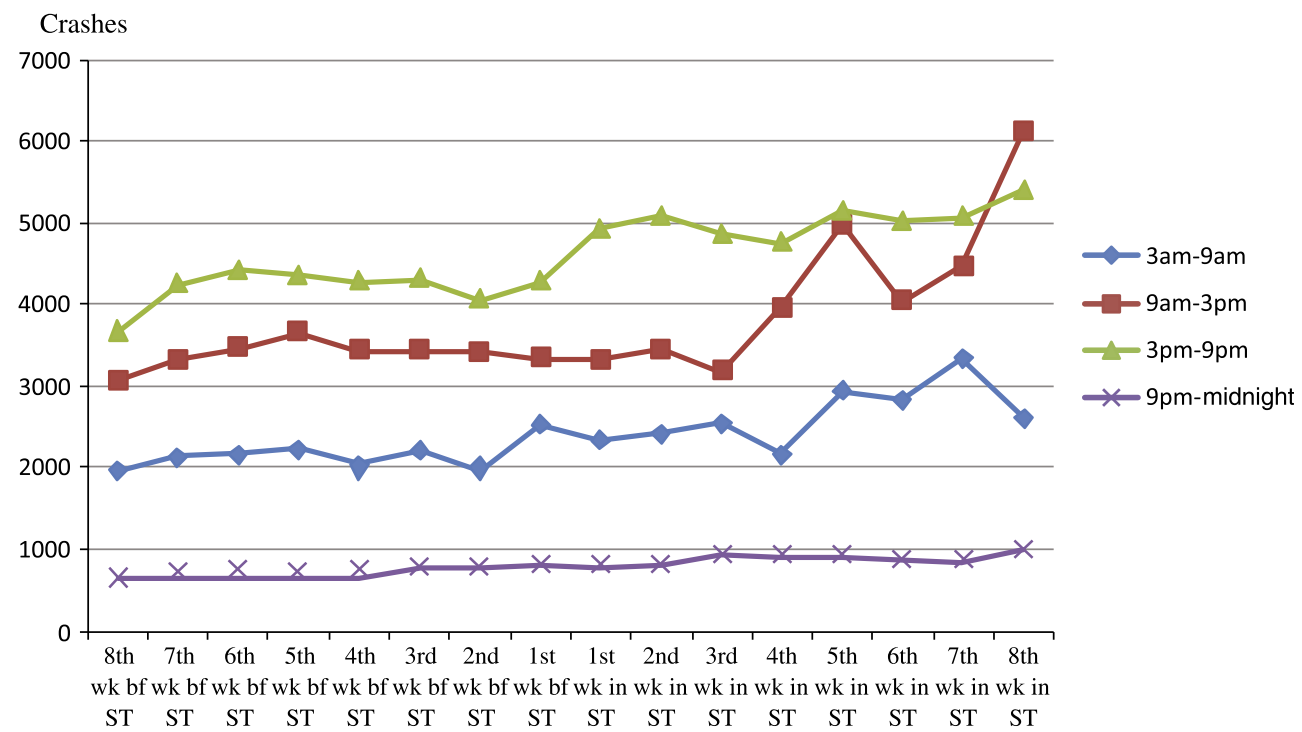

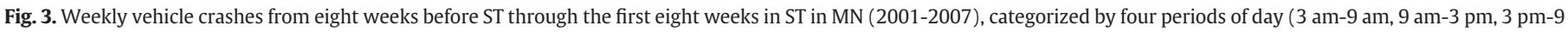
pm, 9 pm-midnight).

The second aspect of the question concerns the issue of exposure to traffic. It would be ideal to use vehicle travel by hour of day, but this information is not available statewide. But we can obtain hourly traffic volume data on some major roads, which are counted by Automatic Traffic Recorder Stations (ATR) located on the state's interstates, trunk highways, county state aid highways, and municipal state aid streets. The ATR data are maintained by the MN Traffic Forecast and Analysis Section of the Office of Transportation data and Analysis. ${ }^{2}$ In this paper total traffic volumes from all ATR stations in different dayparts are used to indicate changes in the amount of travel statewide. ${ }^{3}$ The basic statistics of crashes and ATR traffic volumes in different periods of a day from 2001 to 2007 are shown in Table 4.

\footnotetext{
2 The data can be downloaded from http://www.dot.state.mn.us/traffic/data/atr/atr. html.

${ }^{3}$ It is assumed that the fluctuation of traffic volumes in different dayparts from the ATR data set is representative of the general trend of traffic flows statewide.
}

As noted above, we categorize crashes by four dayparts. The dependent variables are statewide daily vehicle crashes given a period of day from 2001 to 2007. Regarding dependent variables, we are mainly interested in dummy variables for the first Sunday of DST, first Monday of DST, first Sunday of ST, first Monday of ST, and the rest of the days of DST (the base case being the rest of the days in ST). Other independent variables include: traffic volumes (from statewide ATR stations); weather indicators such as rain and snow; dummy variables for year, dummy variables for month; day length ${ }^{4}$; monthly gas price statewide. It should be noted that dummy variables for month and day length (sunlight hours per day) are included to separate the seasonal effects from DST. To elaborate, monthly dummy variables indicate

\footnotetext{
${ }^{4}$ Day length is calculated as the period between the rising and setting of the sun The statewide sunrise/sunset time is averaged over sunrise/sunset times of all counties in Minnesota. The data set was downloaded from the website of Astronomical Applications Department of the U.S. Naval Observatory: http://aa.usno.navy.mil/data/ docs/RS-OneYear.php.
} 


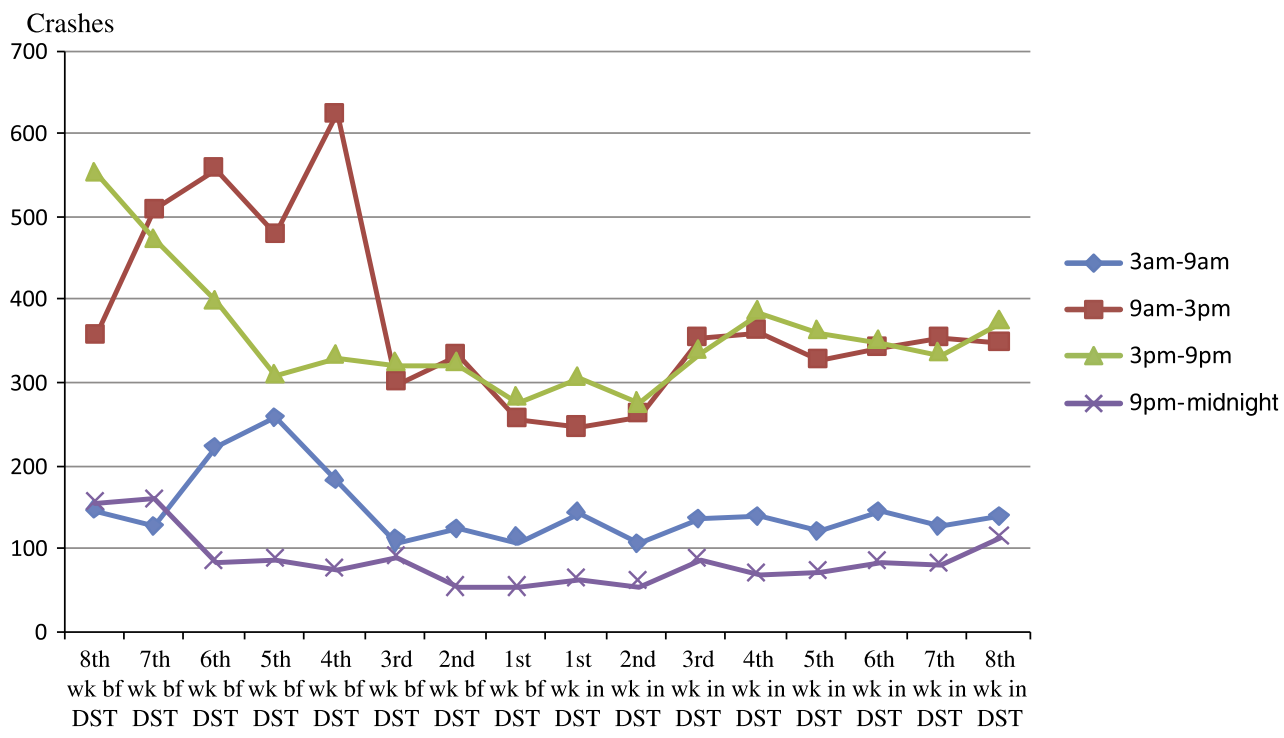

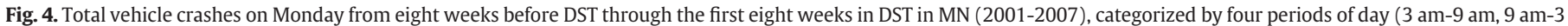
pm, 3 pm-9 pm, 9 pm-12 midnight).

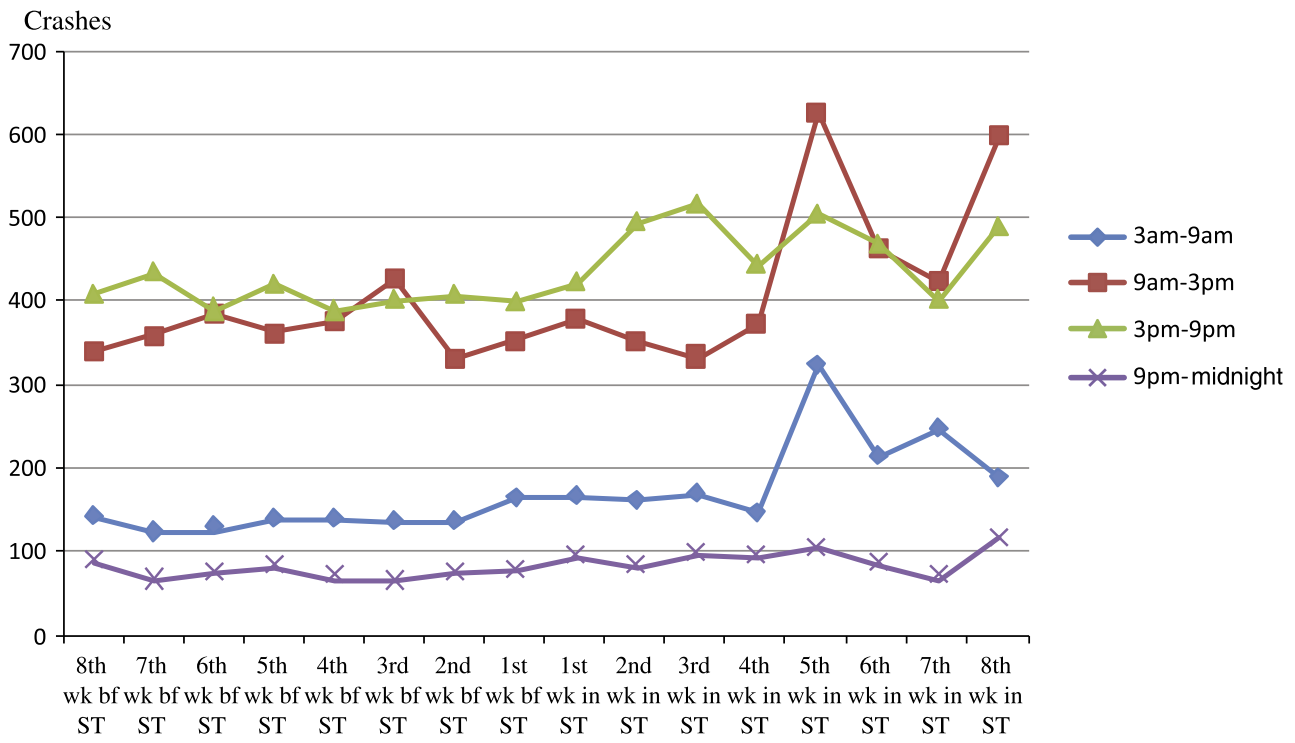

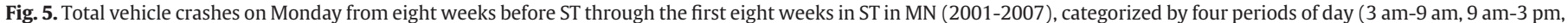
3 pm-9 pm, 9 pm-12 midnight).

seasonal effects on a monthly basis, while day length is used to represent the effect of hours of daylight.

\section{The models}

The dependent variables are crash counts, so the Poisson or negative binomial distribution is often used to describe them (Long, 1997). Deviance and Pearson Chi-square divided by the degrees of freedom are used to detect over-dispersion and under-dispersion. If the value is larger than 1 , then variance is larger than the mean, indicating overdispersion, and under-dispersion if the value is less than 1 . For count data with over-dispersion, the negative binomial distribution is often used. Our initial analysis reveals that the Minnesota crash data show over-dispersion. We further test the null hypothesis equality of mean and variance imposed by the Poisson distribution against the alternative that the variance exceeds the mean. The method we use is based on Cameron and Trivedi (1998): first we run the regression model using negative binomial distribution, and keep the value of $L L_{n b}$ (log- likelihood value); second, the log-likelihood value for fitting the Poisson distribution $\left(L L_{p}\right)$ is also documented; third, we calculate the log likelihood ratio statistic of $-2\left(L L_{p}-L L_{n b}\right)$. The asymptotic distribution of the log likelihood ratio statistic follows the Chi-square distribution with one degree of freedom. For all our models, we reject the null hypothesis that the mean equals and the variance at the 5\% level.

Table 4

Descriptive statistics of crashes and traffic volumes.

\begin{tabular}{llcrrr}
\hline & Time period & \multicolumn{1}{l}{ Mean } & \multicolumn{1}{l}{ St. dev. } & \multicolumn{1}{c}{ Min } & \multicolumn{1}{c}{ Max } \\
\hline Crashes & 3 am-9 am & 42.78 & 3.30 & 5 & 360 \\
& 9 am-3 pm & 75.12 & 41.06 & 19 & 562 \\
& 3 pm-9 pm & 84.74 & 33.01 & 23 & 483 \\
Traffic volume & 9 pm-midnight & 21.89 & 13.51 & 1 & 108 \\
& 3 am-9 am & 415596 & 160994 & 76469 & 574082 \\
& 9 am-3 pm & 792097 & 77569 & 363397 & 1015998 \\
& 3 pm-9 pm & 813235 & 97030 & 292490 & 1004692 \\
& 9 pm-midnight & 177408 & 32536 & 49633 & 255546
\end{tabular}


Table 5

Regressing $\log$ (traffic) on days in daylight saving time (2001-2007).

\begin{tabular}{|c|c|c|c|c|c|}
\hline \multirow[t]{2}{*}{ Dependent Var. } & \multicolumn{5}{|c|}{ Log-traffic volumes in the following periods } \\
\hline & 3 am-9 am & 9 am-3 pm & $3 \mathrm{pm}-9 \mathrm{pm}$ & 9 pm-midnight & all day \\
\hline 1st Sunday(DST) & $0.004(0.072)$ & $-0.008(0.023)$ & $-0.005(0.030)$ & $-0.057(0.032)$ & $-0.009(0.027)$ \\
\hline 1st Monday(DST) & $0.090(0.072)$ & $-0.006(0.023)$ & $0.039(0.030)$ & $0.066(0.032) *$ & $0.033(0.027)$ \\
\hline Rest of days(DST) & $0.017(0.027)$ & $0.015(0.009)$ & $0.045(0.011)^{* *}$ & $0.049(0.012) *$ & $0.03(0.010)^{* *}$ \\
\hline 1st Sunday(ST) & $0.028(0.072)$ & $0.0003(0.023)$ & $-0.005(0.030)$ & $-0.059(0.032)^{*}$ & $-0.006(0.027)$ \\
\hline 1st Monday(ST) & $0.114(0.067)$ & $0.010(0.021)$ & $0.026(0.027)$ & $0.0324(0.029)$ & $0.039(0.025)$ \\
\hline rain & $-0.032(0.013) *$ & $-0.025(0.005)^{* *}$ & $-0.029(0.006)^{* *}$ & $-0.049(0.006)^{* *}$ & $-0.021(0.005)^{* *}$ \\
\hline snow & $-0.059(0.017)^{* *}$ & $-0.092(0.005)^{* *}$ & $-0.115(0.007)^{* *}$ & $-0.091(0.007)^{* *}$ & $-0.079(0.006)^{* *}$ \\
\hline cloudy & $0.002(0.008)$ & $-0.002(0.002)$ & $-0.008(0.003) *$ & $-0.011(0.003)^{* *}$ & $-0.008(0.003)^{* *}$ \\
\hline windy & $-0.040(0.025)$ & $0.014(0.015)$ & $0.0003(0.018)$ & $0.0182(0.013)$ & $-0.001(0.016)$ \\
\hline mon & $1.246(0.014)^{* *}$ & $0.068(0.004)^{* *}$ & $0.124(0.006)^{* *}$ & $0.056(0.006)^{* *}$ & $0.023(0.005)^{* *}$ \\
\hline tue & $1.329(0.013)^{* *}$ & $0.078(0.004)^{* *}$ & $0.160(0.005)^{* *}$ & $0.153(0.006)^{* *}$ & $0.270(0.005)^{* *}$ \\
\hline wed & $1.333(0.013)^{* *}$ & $0.096(0.004)^{* *}$ & $0.179(0.005) * *$ & $0.192(0.006)^{* *}$ & $0.287(0.005)^{* *}$ \\
\hline thur & $1.316(0.013)^{* *}$ & $0.115(0.004)^{* *}$ & $0.186(0.005)^{* *}$ & $0.248(0.006)^{* *}$ & $0.299(0.005)^{* *}$ \\
\hline fri & $1.288(0.013)^{* *}$ & $0.213(0.004)^{* *}$ & $0.253(0.005) * *$ & $0.408(0.006)^{* *}$ & $0.364(0.005)^{* *}$ \\
\hline sat & $0.498(0.013) * *$ & $0.131(0.004)^{* *}$ & $-0.00007(0.006)^{* *}$ & $0.331(0.006)^{* *}$ & $0.128(0.005)^{* *}$ \\
\hline y2002 & $-0.003(0.014)$ & $0.008(0.004)$ & $-0.005(0.006)$ & $0.001(0.006)$ & $0.0002(0.005)$ \\
\hline y2003 & $-0.016(0.013)$ & $-0.0005(0.004)$ & $-0.016(0.005)^{* *}$ & $-0.006(0.006)$ & $-0.009(0.005)$ \\
\hline y2004 & $0.036(0.016) * *$ & $0.035(0.005)^{* *}$ & $0.014(0.006)^{* *}$ & $0.028(0.007)^{* *}$ & $0.025(0.006)^{* *}$ \\
\hline y2005 & $0.067(0.021)^{* *}$ & $0.058(0.007)^{* *}$ & $0.035(0.008)^{* *}$ & $0.041(0.009)^{* *}$ & $0.047(0.008)^{* *}$ \\
\hline y2006 & $0.067(0.026)^{* *}$ & $0.059(0.008)^{* *}$ & $0.032(0.011) * *$ & $0.031(0.0112)^{* *}$ & $0.045(0.010)^{* *}$ \\
\hline y2007 & $0.050(0.029)$ & $0.045(0.009)^{* *}$ & $0.008(0.012)^{* *}$ & $-0.001(0.013)$ & $0.024(0.011) *$ \\
\hline Feb. & $0.052(0.022) *$ & $0.013(0.007)$ & $0.023(0.009) * *$ & $0.016(0.009)$ & $0.020(0.008) *$ \\
\hline Mar. & $0.085(0.032)^{* *}$ & $0.023(0.010)^{* *}$ & $0.040(0.013)^{* *}$ & $0.0004(0.014)$ & $0.037(0.012)^{* *}$ \\
\hline Apr. & $0.110(0.049)^{*}$ & $0.043(0.016)^{* *}$ & $0.050(0.020)^{*}$ & $0.015(0.021)$ & $0.053(0.018) *$ \\
\hline May & $0.102(0.061)$ & $0.049(0.019)^{* *}$ & $0.049(0.025) *$ & $0.0436(0.026)$ & $0.057(0.023) *$ \\
\hline June & $0.157(0.067)$ & $0.083(0.021)^{* *}$ & $0.085(0.0273)^{* *}$ & $0.136(0.029)^{* *}$ & $0.099(0.025)^{* *}$ \\
\hline July & $0.084(0.064)$ & $0.075(0.020)^{* *}$ & $0.054(0.026)^{*}$ & $0.156(0.028)^{* *}$ & $0.077(0.024)^{* *}$ \\
\hline Aug. & $0.138(0.054)^{* *}$ & $0.109(0.017)^{* *}$ & $0.086(0.022)^{* *}$ & $0.141(0.023)^{* *}$ & $0.104(0.020)^{* *}$ \\
\hline Sep & $0.117(0.0424)^{* *}$ & $0.078(0.013)^{* *}$ & $0.063(0.0174)^{* *}$ & $0.028(0.018)$ & $0.071(0.016)^{* *}$ \\
\hline Oct. & $0.142(0.033)^{* *}$ & $0.099(0.010)^{* *}$ & $0.077(0.0135)^{* *}$ & $0.035(0.014) *$ & $0.087(0.012) * *$ \\
\hline Nov. & $0.070(0.018)^{* *}$ & $0.093(0.006)^{* *}$ & $0.059(0.007)^{* *}$ & $0.056(0.008)^{* *}$ & $0.071(0.007)^{* *}$ \\
\hline Dec. & $-0.025(0.018)$ & $0.094(0.006)^{* *}$ & $0.035(0.007)^{* *}$ & $0.119(0.008)^{* *}$ & $0.052(0.007)^{* *}$ \\
\hline daylight hours & $0.003(0.010)$ & $0.013(0.003)^{* *}$ & $0.003(0.004)$ & $0.015(0.004)^{* *}$ & $0.006(0.004)$ \\
\hline gas price (log) & $-0.042(0.042)$ & $-0.056(0.013)^{* *}$ & $-0.031(0.0170)$ & $-0.047(0.018)^{* *}$ & $-0.041(0.0155)^{* *}$ \\
\hline$R^{2}$ & 0.89 & 0.70 & 0.68 & 0.83 & 0.79 \\
\hline
\end{tabular}

** statistically significant at the $1 \%$ level.

* statistically significant at the $5 \%$ level.

Note 1: the OLS model is used to run the regressions.

Note 2: number in (parentheses) indicates std. error.

Therefore, the negative binomial distribution is used to characterize the crash counts in this paper.

Among the independent variables, special attention is paid to the traffic volume variable in that we suspect that it may be an endogenous one. Our model fit tests show that the variable of traffic is endogenous in all our models. Based on Wooldridge (2003), the 2SLS model can be considered if an independent variable is endogenous and the instrumental variables (IV) of this variable are uncorrelated with crashes. In our search for the IVs, we have found that the dummy variables for day of week are highly associated with traffic yet are not correlated with crashes at the $5 \%$ level; moreover, our tests further show that gas price (at the monthly level statewide) is also uncorrelated with crashes. Therefore dummy variables for day of week and the variable of gas price are used as instrumental variables (IV) for traffic. ${ }^{5}$ Therefore the 2SLS model is adopted in our analysis.

We also look at fatal crashes statewide. Yet the fatal crash data, when grouped by different dayparts, display obvious under-dispersion, especially for 3 a.m.-9 a.m. (most of the days where fatal crashes happen only have one or two observations). Therefore we examine fatal crash data on a daily basis; the traffic variable is calculated as daily average traffic volume from all ATR stations. The model fit test also allows us to use the 2SLS model; the model structure is otherwise the same as other models mentioned above.

\footnotetext{
${ }^{5}$ In two of the four models, the correlation between gas price and traffic is not statistically significant; but we still include them in the model for the convenience of comparing the results with those of other models.
}

\section{Results and analysis}

A 2SLS model includes two functions: the reduced function to predict traffic and the structural function to predict crashes. These are discussed in turn.

\subsection{Traffic}

In the reduced function, traffic volumes are used as dependent variables, with day-of-week dummy variables and gas price being instrumental variables; dummy variables for year, month, and weather are also included. The hypothesis is that all else equal, weekdays are associated with more traffic than Sunday in daytime; higher gas price is associated with lower traffic volume. The results for the reduced functions are listed in Table 5; we differentiate the estimated coefficients at the $1 \%$ and $5 \%$ level. As can be seen, the coefficients of first Sunday and first Monday in DST are generally not statistically significant (except for the first Monday in DST during 9 a.m.-midnight), meaning that traffic in the first two days of DST, ceteris par ribus, is no different from an ordinary day in ST. The rest of the days in DST, while not statistically significant in the 3 a.m.-9 a.m. or 9 a.m.-3 p.m. dayparts, are positively associated with traffic during 3 p.m.- 9 p.m. and 9 p.m.-midnight. These results accord with our hypotheses that one more hour daylight in the afternoon in DST encourages more out-of-home activities, and thus results in more vehicles on the road. The signs of the coefficients of other variables are consistent with our hypotheses too. For example, during the first two dayparts: 3 a.m.-9 a.m. and 9 a.m.-3 p.m., traffic in weekdays 
are higher than weekends; yet the opposite holds for dusk and night (probably due to night-time activities on weekends). Moreover, many of the monthly dummy variables are statistically significant, displaying a seasonal trend; the coefficients of day length, representing the impact of daily sunlight differences on traffic, are positive; yet the variable is only statistically significant for the off-peak 9 a.m.-3 p.m. and 9 p.m.-midnight periods.

\subsection{Crashes}

After obtaining the OLS estimate of traffic volume, we employ it as an independent variable in our structural function with crashes as the dependent variable. Table 6 shows the results of the structural forms given different time periods. The coefficient of first Sunday of DST equals 0.026 (the increase may result from our previous hypothesis that losing one hour's sleep affects drivers' behavior); however, it is not statistically significant. During 3 p.m.-9 p.m., the coefficient of the first Sunday in DST equals -0.29 , suggesting approximately $0.28 \%$ fewer crashes on the first day of DST than a day in ST. We also find that during mid-day (9 a.m.-3 p.m.) the first day of DST also has a negative and statistically significant coefficient, but the rest of the days in DST are not statistically significant; it is still unclear why the crashes on the mid-day of the first day in DST are affected, but it must be remembered this first day of DST only occurs on 7 days between 2001 and 2007, so may be anomalous. For the rest of the days in DST, they have negative and statistically significant coefficients for most periods of day except for 9 a.m.-3 p.m. In particular, for sunset and dusk period, the decrease of crashes may be attributed to longer visibility for drivers. Furthermore, none of the estimates for the first Sunday of ST and first Monday of ST are statistically significant, which probably illustrates that crashes on the first two days of ST are no different from other days in ST.

Clearly, traffic has a salient impact on crashes. Particularly for 3 p.m.9 p.m., a 1\% increase of traffic volume, all else equal, is associated with
Table 7

The overall effect of DST on crashes(log form), MN crashes data, 2001-2007 (base case: days in ST).

\begin{tabular}{llllll}
\hline & 3 am-9 am & 9 am-3 pm & 3 pm-9 pm & 9 pm-midnight & $\begin{array}{l}\text { Fatal } \\
\text { (all day) }\end{array}$ \\
\hline $\begin{array}{c}\text { first Sunday } \\
\text { in DST }\end{array}$ & - & -0.367 & -0286 & - & - \\
$\begin{array}{c}\text { first Monday } \\
\text { in DST }\end{array}$ & - & - & -0.246 & 0.107 & - \\
$\begin{array}{c}\text { Rest of the } \\
\text { days in DST }\end{array}$ & -0.164 & - & -0.090 & -0.075 & -0.010 \\
\hline
\end{tabular}

$2.2 \%$ more crashes. Take note that the exposure issue is also influenced by DST. To assess the overall effect of DST on crashes, therefore, we need to consider both the impact of DST per se and exposure to traffic affected by DST (using path analysis). For example, for 3 p.m.-9 a.m., the overall effect of the rest of the days in DST on log-crashes is calculated as: $0.045 \times 2.214-0.190=-0.090$. Thus, a day in DST, all else equal, is associated with about $0.09 \%$ fewer crashes than a day in ST. This reminds us that the benefit of better visibility during dusk may be diminished (but not eliminated) by the corresponding uptick in traffic.

The final results of the influence of DST on crashes are described in Table 7 (in calculation we only consider the statistically significant coefficients). They demonstrate that a day DST, largely speaking, is associated with fewer crashes than its counterpart in ST when all else is equal. In addition, we do not find a statistically significant rise of crashes on the first day of DST during 3 a.m.-9 a.m.

\subsection{Fatal crashes}

Our results from the fatal crash data show that none of the coefficients for the first Sunday day in DST, first Monday in DST, and the rest of days in DST are statistically significant (after controlling for

Table 6

Regressing vehicle crashes on days in daylight saving time (MN crash data , 2001-2007).

\begin{tabular}{|c|c|c|c|c|c|}
\hline \multirow[t]{2}{*}{ Dependent Var. } & \multicolumn{5}{|c|}{ Log-crashes in the following periods } \\
\hline & 3 am-9 am & $9 \mathrm{am}-3 \mathrm{pm}$ & 3 pm-9 pm & 9 pm-midnight & Fatal(all day) \\
\hline 1st Sunday(DST) & $0.026(0.171)$ & $-0.367(0.134)^{* *}$ & $-0.286(0.111)^{* *}$ & $-0.032(0.179)$ & $-0.346(0.410)$ \\
\hline 1st Monday(DST) & $-0.201(0.160)$ & $-0.115(0.128)$ & $-0.246(0.106)^{*}$ & $-0.293(0.178)$ & $0.168(0.234)$ \\
\hline Rest of days(DST) & $-0.164(0.062)^{* *}$ & $-0.093(0.049)$ & $-0.190(0.039) * *$ & $-0.155(0.060) * *$ & $-0.058(0.113)$ \\
\hline 1st Sunday(ST) & $-0.168(0.170)$ & $-0.142(0.129)$ & $-0.129(0.1066)$ & $0.237(0.164)$ & $0.168(0.234)$ \\
\hline 1st Monday(ST) & $-0.204(0.147)$ & $-0.080(0.116)$ & $0.126(0.092)$ & $-0.024(0.146)$ & $-0.167(0.256)$ \\
\hline traff $(\log )$ & $0.634(0.017)^{* *}$ & $1.978(0.104)^{* *}$ & $2.214(0.059) * *$ & $1.634(0.058)^{* *}$ & $-0.323(0.104) *$ \\
\hline rain & $0.296(0.029) * *$ & $0.375(0.025)^{* *}$ & $0.238(0.020) * *$ & $0.314(0.028)^{* *}$ & $0.006(0.056)$ \\
\hline snow & $0.639(0.037)^{* *}$ & $0.926(0.033) * *$ & $0.752(0.025)^{* *}$ & $0.814(0.033)^{* *}$ & $0.082(0.065)$ \\
\hline cloudy & $-0.033(0.018)^{* *}$ & $-0.013(0.013)$ & $0.0106(0.011)$ & $0.040(0.018) *$ & $-0.002(0.031)$ \\
\hline windy & $0.100(0.057)^{* *}$ & $-0.077(0.085)$ & $-0.010(0.063)$ & $0.038(0.063)$ & $0.052(0.089)$ \\
\hline y2002 & $-0.028(0.030)$ & $-0.067(0.023) * *$ & $-0.003(0.019)$ & $-0.069(0.030)^{*}$ & $0.088(0.051)$ \\
\hline y2003 & $-0.288(0.030)^{* *}$ & $-0.313(0.023)^{* *}$ & $-0.056(0.019)^{* *}$ & $0.291(0.029){ }^{* *}$ & $0.056(0.051)$ \\
\hline y2004 & $-0.126(0.030)^{* *}$ & $-0.248(0.023)^{* *}$ & $-0.033(0.019)$ & $0.288(0.029)^{* *}$ & $-0.015(0.052)$ \\
\hline y2005 & $-0.191(0.030)^{* *}$ & $-0.310(0.023)^{* *}$ & $-0.076(0.0191)^{* *}$ & $0.256(0.029)^{* *}$ & $-0.018(0.053)$ \\
\hline y2006 & $-0.223(0.030)^{* *}$ & $-0.385(0.023) * *$ & $-0.149(0.019)^{* *}$ & $0.197(0.030)^{* *}$ & $-0.022(0.054)$ \\
\hline y2007 & $-0.231(0.030)^{* *}$ & $-0.344(0.023)^{* *}$ & $-0.128(0.0194)^{* *}$ & $0.154(0.030)^{* *}$ & $-0.067(0.055)$ \\
\hline Feb. & $0.177(0.047)^{* *}$ & $-0.010(0.037)$ & $0.004(0.031)$ & $-0.0120(0.046)$ & $-0.161(0.091)$ \\
\hline Mar. & $-0.001(0.071)$ & $-0.116(0.056) *$ & $-0.181(0.046)^{* *}$ & $-0.100(0.070)$ & $-0.300(0.133) *$ \\
\hline Apr. & $0.012(0.109)$ & $-0.091(0.085)$ & $0.007(0.067)$ & $0.057(0.105)$ & $-0.071(0.192)$ \\
\hline May & $0.208(0.135)$ & $0.156(0.106)$ & $0.208(0.087) *$ & $0.240(0.131)$ & $-0.080(0.238)$ \\
\hline June & $0.301(0.149) *$ & $0.280(0.116)^{* *}$ & $0.229(0.095) *$ & $0.401(0.144)^{* *}$ & $-0.025(0.261)$ \\
\hline July & $0.178(0.142)$ & $0.228(0.111) *$ & $0.214(0.091) *$ & $0.261(0.138)$ & $-0.049(0.248)$ \\
\hline Aug. & $0.063(0.118)$ & $0.094(0.093)$ & $0.081(0.076)$ & $0.060(0.115)$ & $0.090(0.209)$ \\
\hline Sep & $0.201(0.093)$ & $-0.027(0.073)$ & $0.119(0.060)^{* *}$ & $0.067(0.090)$ & $-0.007(0.166)$ \\
\hline Oct. & $0.055(0.073)$ & $-0.153(0.059) * *$ & $0.031(0.047)$ & $0.084(0.071)$ & $0.121(0.130)$ \\
\hline Nov. & $-0.091(0.039) *$ & $-0.273(0.032) * *$ & $0.019(0.026)$ & $-0.018(0.039)$ & $0.036(0.072)$ \\
\hline Dec. & $-0.056(0.039)$ & $-0.086(0.032)^{* *}$ & $0.010(0.025)$ & $-0.124(0.039)$ & $0.141(0.069) *$ \\
\hline daylight hours & $-0.1010(0.023)^{* *}$ & $-0.090(0.018)^{* *}$ & $-0.051(0.015)^{* *}$ & $-0.064(0.022)^{* *}$ & $0.039(0.040)$ \\
\hline
\end{tabular}

** statistically significant at the $1 \%$ level.

* statistically significant at the $5 \%$ level.

Note 1: the negative binomial (NB) model is used to run the regressions.

Note 2: number in (parentheses) indicates std. error. 
traffic and months). Yet it is interesting to notice that the coefficient of traffic in the structural model equals -0.323 and is statistically significant at the $5 \%$ level, meaning that the increase of traffic is associated with a decrease of fatal crashes. This may be because higher traffic volumes limit vehicles' speed, which makes drivers less likely to drive recklessly; a similar theory can be found in John Adams's thoughts in Smeed's Law (Adams, 1987). In the reduced function with traffic as the dependent variable, the coefficient of the rest of the days in DST equals 0.027. The overall effect of DST on vehicle crashes can be calculated as $-0.323 \times 0031=0.010$, indicating that a day in DST, all else equal, is associated with about $0.008 \%$ fewer fatal crashes than a day in ST.

\section{Conclusions}

Considering the issue of exposure to traffic, this paper explores long- and short-term effects of DST on vehicle crashes. The contribution of this research includes two aspects. First, we separate the effects of DST on traffic volume and the effect of DST per se on crashes. The two stage least square models are further developed to examine crashes in four periods of day (including dawn and dusk periods). Second, we have looked at crashes at different periods of day, which is convenient for explaining the possible causes for the effects. Our results show that DST per se, by providing one more hour's visibility in the afternoon, can help reduce crashes during and after dusk; but it can also increase traffic. Overall, we find that DST, all else equal, is associated with fewer crashes for most dayparts; in addition, DST is also correlated with fewer fatal crashes than ST.

\section{Acknowledgements}

We thank Nathan Drews and Gene Hicks from the Minnesota Department of Transportation for providing the crash data set for this study.

\section{References}

Adams, J. (1987). Smeed's Law: some further thoughts. Traffic Engineering and Control, $28,70-73$.

Adams, J. M. (2005). Year-round daylight saving and serious or fatal road traffic injuries in children in the Northeast of England. Journal of Public Health, 27(4), 316-317.

Broughton, J., Hazelton, M., \& Stone, M. (1999). Influence of light level on the incidence of road casualties and the predicted effect of changing 'summertime'. Journal of the Royal Statistical Society: Series A, 162(2), 137-175.

Broughton, J., \& Sedmand, R. J. (1989). The potential effects on road causalties of double British Summer Time, TRL report 228. Crowthorne: Transport Research Laboratory.

Broughton, J., \& Stone, M. (1998). A new assessment of the likely effects on road accidents of adopting SDST, TRL report 368. Crowthorne: Transport Research Laboratory.
Cameron, A., \& Trivedi, P. (1998). Regression Analysis of Count Data. Cambridge: Cambridge University Press.

Coate, D., \& Markowitz, S. (2003). The effects of daylight and daylight saving time on us pedestrian fatalities and motor vehicle occupant fatalities. Accident Analysis and Prevention, 36(3), 351-357.

Coren, S. (1996a). Acciental death and shift to daylight saving time. Perceptual and Motor Skills, 83, 921-922.

Coren, S. (1996b). Daylight savings time and traffic accidents. The New England Journal of Medicine, 334, 924.

Fatehi, S. (2009). Daylight Chart 3.0. http://daylightchart.sourceforge.net/sunposition/. Ferguson, S. A. (1995). Daylight savings time and motor vehicle crashes: the reduction in pedestrian and vehicle occupant fatalities. American Journal of Public Health, 85 (1), 92-95.

Hicks, G. J., Davis, J. W., \& Hicks, R. A. (1998). Fatal alcohol-related traffic crashes increase subsequent to changes to and from daylight savings time. Perceptual and Motor Skills, 86(3 Pt 1), 879-882.

Hicks, R. A., Lindseth, K., \& Hawkins, J. (1983). Daylight savings time changes increase traffic accidents. Perceptual and Motor Skills, 56, 64-66.

Hillman, M. (1989). More daylight less accidents. Traffic Engineering and Control, 4(30) $191-193$.

Lambe, M., \& Cummings, P. (2000). The shift to and from daylight savings time and motor vehicle crashes. Accident Analysis and Prevention, 32, 609-611.

Ledger, D. (1994). The cost of sleep related accidents: a report for the national commission on sleep disorders research. Sleep, 17, 84-93.

Long, J. (1997). Regression Models for Categorical and Limited Dependent Variables. Thousand Oaks, CA: Sage Publications Inc.

Meyerhoff, N. J. (1978). The influence of daylight saving time on motor vehicle fatal traffic accidents. Accident Analysis and Prevention, 10, 207-221.

Sood, N., \& Ghosh, A. (2007). The short and long run effects of daylight saving time on fatal automobile crashes.B.E. Journal of Economic Analysis \& Policy, 7(1) (Article 11).

Stevens, C. R. \& Lord, D. (2006). Evaluating safety effects of daylight savings time on fatal and nonfatal injury crashes in texas. Transportation Research Record, 1953, $147-155$.

Varughese, J., \& Allen, R. P. (2001). Fatal accidents following changes in daylight savings time: the American experience. Sleep Medicine, 2(1), 31-36.

Vincent, A. (1998). Effects of daylight savings time on collision rates. The New England Journal of Medicine, 339, 1167-1168.

Ward, H., Cave, J., Morrison, A., Allsop, R., Evans, A., Kuiper, C., et al. (1994). Pedestrian activity and accident risk, Technical report. London: Automobile Association Foundation for Road Safety Research.

Wooldridge, J. M. (2003). Introductory Econometrics: A Modern Approach. OH: SouthWestern Mason.

Arthur Huang is a Ph.D. student at the Department of Civil Engineering at the University of Minnesota, Twin Cities. He is also enrolled in the Master of Urban and Regional Planning program at the Humphrey Institute of Public Affairs, University of Minnesota. His major research interests are the evolution of transportation and land use, business cluster analysis, and traffic safety. He is a student member of American Planning Association, Institute of Transportation Engineers, and Air \& Waste Management Association.

Dr. David Levinson is an Associate Professor in the Department of Civil Engineering at the University of Minnesota and Director of the Networks, Economics, and Urban Systems (NEXUS) research group. He currently holds the Richard P. Braun/CTS Chair in Transportation. Levinson has authored or edited several books and numerous peer reviewed articles. He is the editor of the Journal of Transport and Land Use. 